\title{
Análise da influência da vegetação nos processos de saturação do solo na bacia hidrográfica do Riacho Fundo, Distrito Federal
}

\author{
Felipe Lima Ramos Barbosa ${ }^{1}$ \\ Edílson de Souza Bias ${ }^{1}$ \\ Cleber Stragliotto ${ }^{1}$ \\ ${ }^{1}$ Universidade Católica de Brasília - UCB \\ CEP - 71966-700 - Brasília, Brasil \\ \{felipel, edilsonb\}@ucb.br \\ cleberstragliotto@gmail.com
}

\begin{abstract}
Brazil is a big country with richness water supplies, and we have been getting big demand about them. So it is unquestionable the development of sustainable techniques to aim a properly water quality and continuous supply. To gain them it is necessary understand the interaction between vegetation cover and water behavior inside the soil. It is an actual and important environmental issue, so this paperwork brings a briefly analysis that is going to help further management efforts in water resources' maintenance and preservation.
\end{abstract}

Palavras-chave: remote sensing, normalized difference vegetation index, soil saturation index, numeric model, multitemporal analysis, sensoriamento remoto, modelo numérico, índice de saturação do solo, índice de vegetação normalizada, análise multitemporal.

\section{Introdução}

O Brasil, país de riquezas minerais e ambientais, possui uma vasta rede hidrográfica, que atende aos mais variados usos consuntivos ${ }^{1}$. Diante de tal demanda faz-se inquestionável a preocupação e desenvolvimento de técnicas sustentáveis que prezem pela qualidade e abastecimento contínuo da água.

Porém a ocupação indevida, aliada a deficiência de ações de planejamento urbano e muitas vezes carente de apoio técnico, afetam a qualidade e as características do escoamento superficial e sub-superficial dessa água, uma vez que reduzem a cobertura vegetal, expondo o solo e gerando problemas ambientais que trazem consequiências sociais e econômicas para os órgãos municipais, estaduais e federais, tais como recuperação de processos erosivos e controle de inundações. Segundo Souza (2003), muitas vezes o progresso urbano é resumido apenas ao desenvolvimento econômico e tecnológico, esquecendo-se os reais custos sociais e, atrelado a este, ambientais.

Uma conseqüência direta da modificação da cobertura vegetal é identificada no padrão de saturação do solo, que por sua vez não consegue conter a água infiltrada, que passa, a partir deste momento, a escoar superficialmente gerando padrões artificiais de drenagem, que unida à má, ou a não existência da infra-estrutura urbana, acarreta efeitos diretos (inundações e destruição de pavimentação) e indiretos (aumento do preço dos alimentos devido à perda de colheitas por alagamento) (DAMACENA, 2008). Segundo Guerra \& Guerra (2003), os principais fatores que influenciam na saturação do solo são: propriedades do solo, características das chuvas, umidade já presente no solo, e cobertura vegetal, principal preocupação deste presente trabalho.

Com o intuito de estimar tais variáveis, vem crescendo no Brasil a utilização de modelos matemáticos que possibilitam, mesmo de forma aproximada, representar a realidade de um determinado ambiente para predizer os futuros processos que ali podem ocorrer. Muitos trabalhos foram desenvolvidos neste âmbito, tais como O'loughlin (1986), entre outros.

\footnotetext{
${ }^{1}$ Consumo significativo de água
} 
Com esse objetivo, foi selecionada a bacia hidrográfica do Riacho Fundo para a identificação dos focos de saturação do solo, utilizando o método desenvolvido por O’loughlin (1986), e a comparação destas áreas com os padrões de índice fotossintético da vegetação, mais precisamente na sua porção urbana.

\section{Metodologia}

\section{1. Área de estudo}

A bacia hidrográfica do Riacho Fundo se encontra na porção oeste do DF, constituinte da região hidrográfica do Paraná, entre as coordenadas UTM 23S 172.373 L/ 8.256.087 N e 182.375 L/ 8.229.489 N. Com área de aproximadamente $217,88 \mathrm{Km}^{2}$, segundo Maia et al (2005), apresenta alta taxa de densidade e diversidade de ocupação, compreendendo áreas comerciais, residenciais e áreas de atividade agrícola, na porção sul. Seus principais afluentes são os córregos Vicente Pires, Guará (margem esquerda) e córrego Coqueiros (margem direita). A Figura 1 mostra a localização bem como a disposição hídrica na bacia em análise.

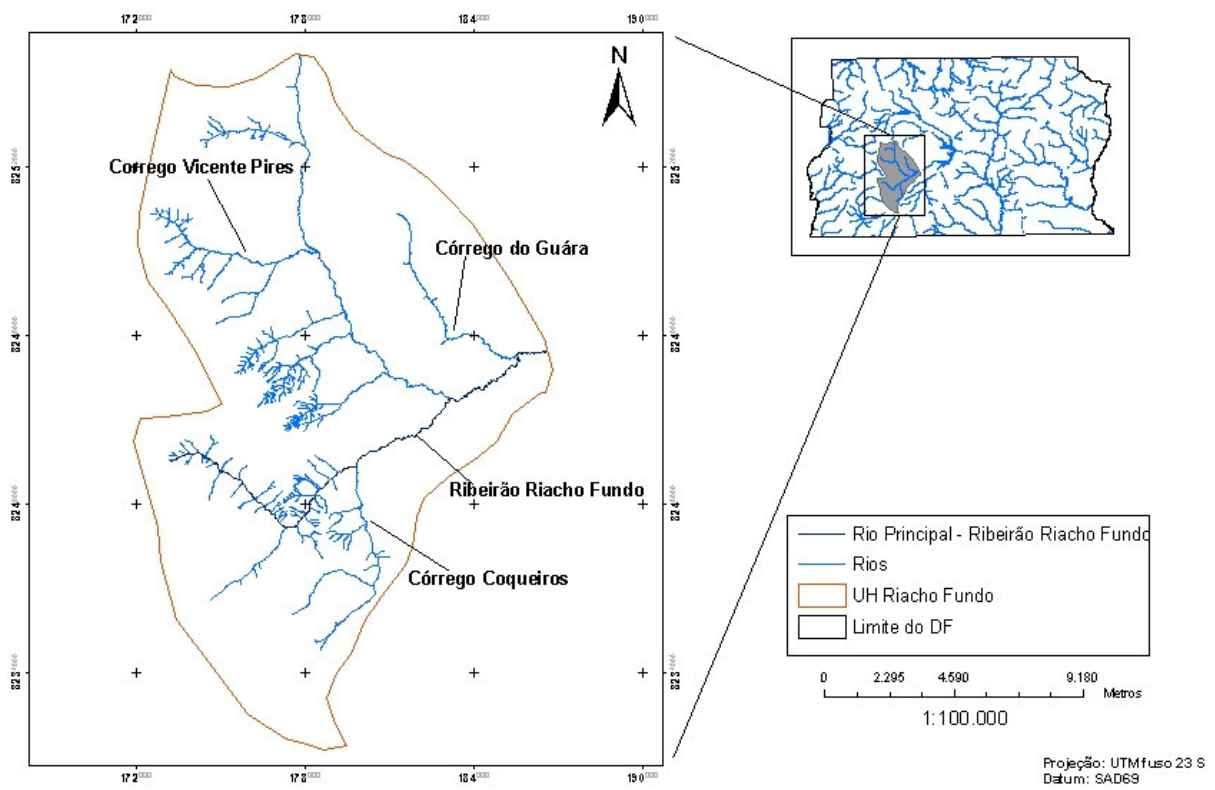

Figura 1 - Mapa de localização e rede hidrográfica da bacia hidrográfica do Riacho Fundo.

O ribeirão principal e os tributários percorrem um grande trecho urbano (Córrego de Vicente Pires) aonde se observam descargas de esgoto e lixo, regiões com plantações agrícolas (nascente do ribeirão Riacho Fundo e córrego Coqueiros), bem como, ruas movimentadas, tais como o Guará ${ }^{2}$ e o setor habitacional Vicente Pires. Segundo Echeverria (2007), a vegetação da bacia hidrografia é típica de cerrado, com presença de matas galerias, arbustos e árvores de grande porte.

Geomorfologicamente, a área de interesse situa-se sobe a chapada de Brasília, com a presença de áreas de dissecação intermediárias do Rio Paranoá, isto é, observa-se a presença das depressões interplanálticas, pediplano de Brasília, e a oeste, parte do pediplano Contagem Rodeador (BARBOSA, 2007 apud ECHEVERRIA, 2007).

Grande parte dos solos é composta entre latossolos e cambissolos, com presença de pequenas áreas de laterita hidromórfica e luvissolos. Segundo o Sistema Brasileiro de

\footnotetext{
${ }^{2}$ Região Administrativa - RA X.
} 
Classificação de Solos - SiBCS (EMBRAPA, 1999), as principais classes são: latossolo vermelho, latossolo vermelho-amarelo e cambissolo, que ocupam cerca de $85,5 \%$ do DF.

\subsection{Modelo de saturação do solo}

O modelo matemático criado por O’loughlin (1986) baseia-se na predição da variável umidade do solo a partir da análise da área de contribuição a montante, precipitação, transmissividade do solo, e declividade. Esse modelo considera a infiltração da água, proveniente da precipitação, até o nível solo-rocha (plano de baixa condutividade), a partir do qual um fluxo sub-superficial vai adotar o caminho preferencial segundo a topografia (declividade), o que resultará em sua posterior acumulação em áreas de baixa altitude, tais como fundos de vale (GUIMARÃES, 2000). Assim existe a possibilidade de saturação do solo ocorrer nestas áreas. A Equação 1 mostra o modelo de saturação, por meio do índice de umidade (W) proposto por O'loughlin (1986).

$$
W=\frac{Q}{T} \cdot \frac{\mathbf{a}}{\mathbf{b} \operatorname{sen} \theta}
$$

Onde: (Q) é o valor de precipitação; (T) é o valor de transmissividade do solo; (a) área de contribuição a montante; (b) é o elemento de contorno no qual passa a precipitação; $\operatorname{sen}(\boldsymbol{\theta})$ é o seno da declividade local (GUIMARÃES, 2000).

Segundo Dietrich (1993) apud Guimarães et al (2003), a razão Q/T corresponde ao controle hidrológico, assim como, a/bsen $\theta$ corresponde ao controle morfométrico de terreno. Desta forma, segundo o modelo, a condição de saturação do solo ocorre quando o fluxo de drenagem a montante ultrapassa a capacidade do solo de transmitir (infiltrar) essa água, isto é, segundo Damacena et al (2008) quando o modelo adotar valores (W) superiores a 1 , indicando áreas susceptíveis à saturação.

\subsection{Estimativa de cobertura vegetal}

Neste trabalho a estimativa de cobertura vegetal foi realizada por meio do índice de vegetação de diferença normalizada (NDVI), que é comumente empregado utilizando a combinação, em forma de razão, dos valores de reflectância da região do vermelho junto ao infravermelho próximo.

Segundo Ponzoni (2001), a resposta da radiância no vermelho possui uma relação inversa não-linear com a biomassa verde, resposta essa devido à constatação de um processo dominante de absorção (proporcional à quantidade de clorofila) por parte de um dossel, ocasionado pelos pigmentos fotossintetizantes. Isso explica a sensibilidade fotossintética com relação a este índice. Já a região do infra-vermelho próximo, as medidas de radiância captadas pelo sensor estão diretamente ligadas ao processo de espalhamento intra e interfoliar, dependentes tanto da quantidade de folhas existentes quanto de sua distribuição e arranjo espacial num respectivo dossel. A Equação 2 mostra a razão normalizada do índice NDVI.

$$
\mathrm{NDVI}=(\mathrm{NIR}-\mathrm{R}) /(\mathrm{NIR}+\mathrm{R})
$$

Este índice, então, identifica as intensidades das atividades fotossintéticas, variando de -1 a 1, isto é, os valores mais elevados estão relacionados com uma maior densidade de cobertura vegetal (VICENS et al,1998).

\subsection{Modelo Digital de Elevação (MDE) e área de contribuição}


Após o ajuste vetorial, os dados de pontos cotados, curvas de nível e hidrografia, na escala de 1:10.000, foram usados para a confecção do MDE a partir da utilização do interpolador Topogrid (HUTCHINSON, 1989) implementado no ArcGIS 9.2, com tamanho de célula (pixel) igual a 2 metros condizente com o padrão planimétrico classe A das Normas Técnicas da Cartografia Nacional, descritas no Decreto ${ }^{0} 89.817$ de 20/06/1984.

Esse interpolador foi escolhido, entre muitos outros existentes, por apresentar a menor média de erro e possibilitar a utilização do vetor da rede hidrográfica no processo de interpolação (FREITAS, 2005).

A etapa subseqüente foi à correção das depressões espúrias por meio da aplicação do algoritmo Fill Sink, garantindo assim a conectividade do fluxo superficial do MDE.

Finalmente com o modelo corrigido, foi calculada a área de contribuição a montante, utilizando o algoritmo Dinf desenvolvido por Tarboton (1997). Segundo Barbosa (2007), a ponderação do fluxo superficial da água é realizada segundo o ângulo entre o escoamento identificado e o caminho preferencial (cardinal ou diagonal) mais próximo a esse, de acordo com a declividade local.

Vale salientar que o modelo de acumulação foi gerado a montante do exutório ${ }^{3}$ da área de interesse.

\subsection{Dados Pluviométricos}

Em virtude da bacia hidrográfica do Riacho Fundo encontrar-se inserida no Distrito Federal, o valor para a precipitação utilizado neste trabalho foi de $20 \mathrm{~mm} /$ dia, uma vez que os dados coletados pelo Instituto Nacional de Meteorologia (INMET) para o DF serviram de base para as análises. Segundo Damacena et al (2008), os valores diários de chuva em torno de $20 \mathrm{~mm} /$ dia foram encontrados com relativa freqüência pelo INMET, no mínimo 12 vezes ao ano desde 2001.

\subsection{Transmissividade do solo}

Os dados de pedologia, base vetorial, foram adquiridos do mapa de reconhecimento de solos da EMBRAPA (1971) para o DF, na escala de 1:100.000. Reduzindo-se a área urbana dos $217,7 \mathrm{Km}^{2}$ da bacia, encontra-se $169 \mathrm{Km}^{2}$ de área pedológica, dos quais, $115,11 \mathrm{Km}^{2}$ são latossolos, 43,89 $\mathrm{Km}^{2}$ são cambissolos, e o restante, cerca de $10 \mathrm{Km}^{2}$, são compostos de gleissolos, laterita hidromórfica e luvissolos.

Devido a esta disparidade entre a área da bacia e área de dados pedológicos decidiu-se normalizar a variável pedologia, isto é, considerou-se o valor médio de transmissividade das classes de latossolo e cambissolo (relativos a 94\%) para a extensão de interesse. As classes de solos diferentes (cerca de $6 \%$ dos dados) não foram consideradas na análise.

Segundo Oliveira et al (2004), os latossolos, vermelho distrófico e latossolo vermelhoamarelo distrófico, analisados em seu trabalho, possuem condutividade hidráulica variando de $10^{-4}$ e $10^{-6}$ para a camada superficial, e $10^{-6}$ e $10^{-7}$ da camada superficial até 15 metros de profundidade. Já os cambissolos, segundo Amaral et al (2007), possuem uma média de condutividade hidráulica igual a 3,08 x $10^{-5}$ com profundidade de até 1,5 metros, valores estes encontrados na respectiva área de estudo do autor.

Segundo Guimarães et al (2003), o parâmetro transmissividade é função do produto da condutividade hidráulica (Ksat) pela espessura do solo (e). A Equação 3 mostra esta relação.

$$
\mathrm{T}=\mathrm{K}_{\text {sat }} \mathrm{e}
$$

\footnotetext{
${ }^{3}$ Segundo Lopes (2008), ponto do curso d'água onde toda a vazão afluente é descarregada.
} 
Assim, para o presente trabalho, considerou-se o parâmetro transmissividade do latossolo e cambissolo, respectivamente, igual a $1,5 \times 10^{-5} \mathrm{~m}^{2} / \mathrm{s}$ e $4,62 \times 10^{-5} \mathrm{~m}^{2} / \mathrm{s}$.

\section{7. Índice da vegetação de diferença normalizada (NDVI)}

Para a estimativa do índice fotossintético da cobertura vegetal foram utilizadas imagens, do sensor LANDSAT TM 5, em três períodos diferentes, dos meses de abril/maio dos anos de 1984/1993/2008. O intuito da análise multitemporal foi averiguar a variação do índice fotossintético da vegetação, nos respectivos anos, e sua importância junto aos locais susceptíveis à saturação.

Primeiramente, com base na imagem NDVI do ano de 1984, foram geradas máscaras referentes as classes "alto índice fotossintético" $(0,5-1)$, "médio índice fotossintético" $(0,35$ - 0,5) e "baixo índice fotossintético" $(0,25$ - 0,35) do fatiamento. Posteriormente, essas mesmas máscaras foram aplicadas, separadamente, nas imagens NDVI dos anos de 1993 e 2008 como base para um subseqüente fatiamento utilizando os mesmos parâmetros definidos. A Figura 2 apresenta os histogramas dos índices NDVI para cada ano.

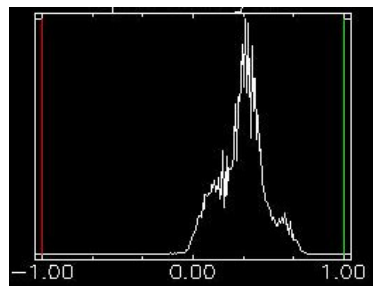

(a)

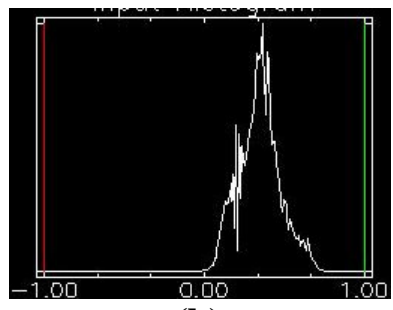

(b)

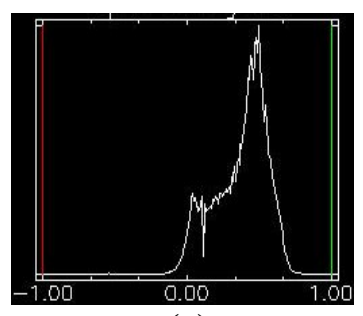

(c)

Figura 2 - Histogramas do índice NDVI para os anos de análise. (a) 1984. (b) 1993. (c) 2008 .

Observa-se certo decaimento na freqüência dos valores positivos próximos a zero, bem como um ganho de valores negativos próximos ao zero. A aplicação do procedimento teve como objetivo quantificar os ganhos e perdas de cada classe de análise no decorrer dos anos.

\section{Resultados e discussões}

\section{1. Área de saturação para a bacia hidrográfica do Riacho Fundo}

O modelo matemático de O'loughlin (1986) estabelece que resultados superiores a 1 estão relacionados às áreas com condições suficientes a virem a saturar. A Figura 3 mostra as áreas de saturação do solo (tons de cor azul) e as áreas não saturáveis (tons de cor bege), junto com a tabela de relação de área $\left(\mathrm{Km}^{2}\right)$ respectiva a cada classe. 

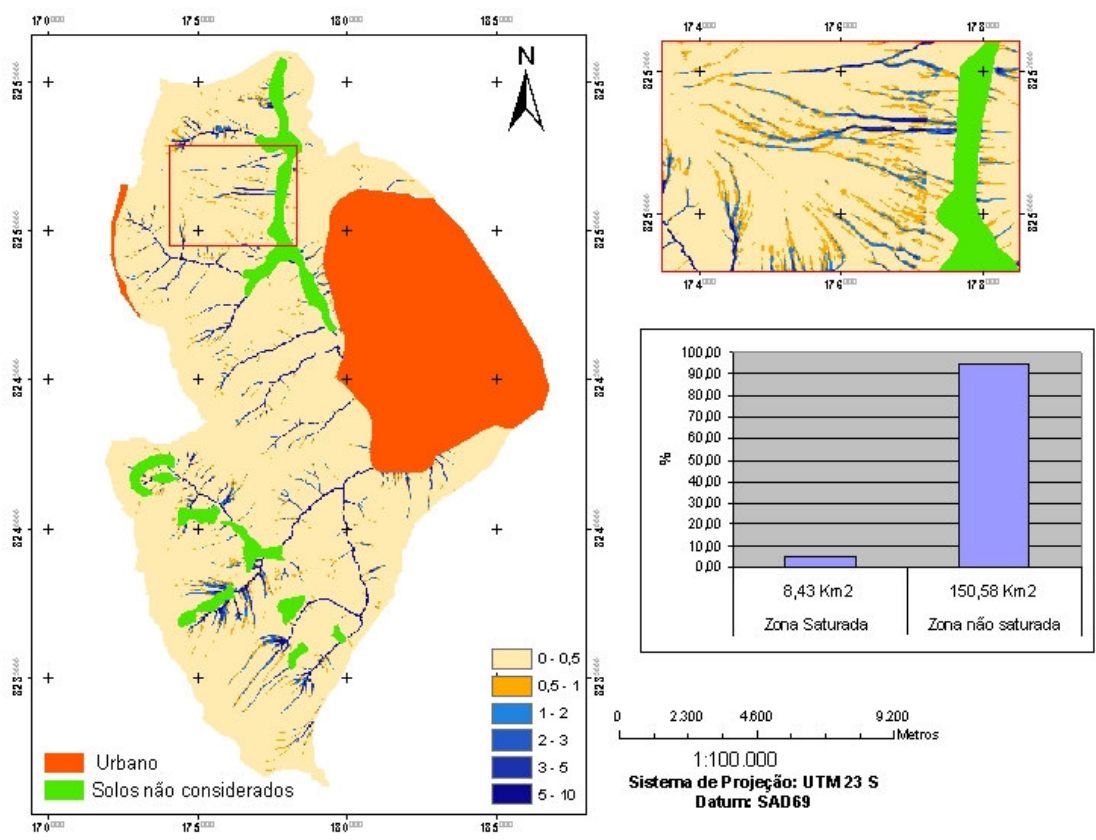

Figura 3 - Saturação do solo da bacia hidrografia Riacho Fundo, 20 mm/dia de chuva.

De acordo com a área modelada, observa-se que a área propicia a saturar está em torno de $5,3 \%\left(8,43 \mathrm{Km}^{2}\right)$ para a quantidade de chuva selecionada. A distribuição espacial destas está, em grande parte, concentradas ao sul da bacia (área de uso agrícola), bem como na porção noroeste (ocupação urbana) onde encontramos, por exemplo, a antiga colônia agrícola Vicente Pires, hoje parcelamento urbano em fase de regularização pela TERRACAP, órgão competente no Distrito Federal.

Com a aplicação do índice NDVI foi possível estimar a mudança temporal da cobertura vegetal, por meio da análise do índice fotossintético. O Figura 4 mostra a relação, para os anos selecionados, da mudança das classes de alto, médio e baixo índice fotossintético, demonstrando a perda ou ganho de vegetação.

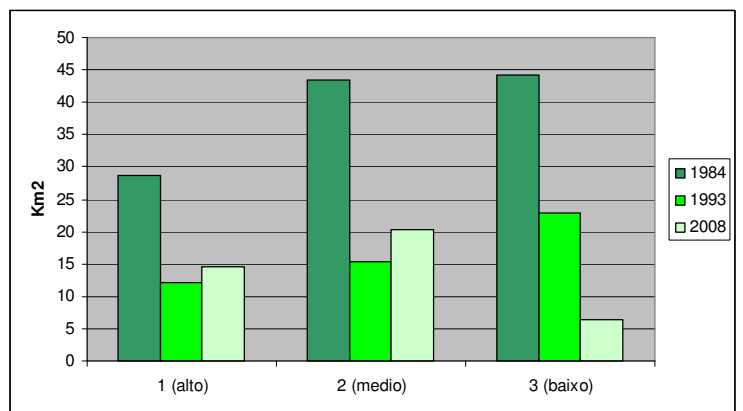

(a)

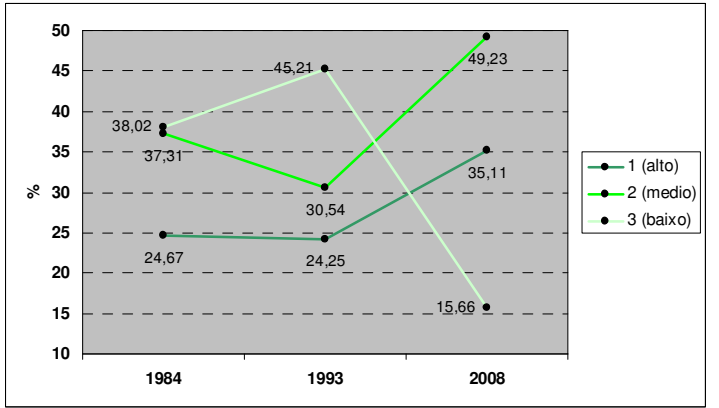

(b)

Figura 4 - Gráficos demonstrando a relação temporal da mudança das classes de índice fotossintético da cobertura vegetal. (a) Relação temporal de ganhos e perdas de cobertura vegetal. (b) Porcentagem de cada classe em relação aos anos de análises.

Observa-se que a cobertura vegetal sofreu perdas, em área, em todas as classes dos anos de 1984 a 1993, isto devido ao processo de ocupação urbana ocorrida a época. Porém, entre 1993 e 2008, foi observada certa recuperação das classes alto e média, com perda expressiva na classe baixa (Figura 4b). Isso pode ser explicado pelo processo de ocupação urbana, que 
tende a ocorrer em relevos mais planos associados a topos de chapada, onde se concentram grande parte dos campos limpos, sujos e cerrado, associados a índices fotossintéticos baixos.

Comparando os locais de perda expressivas de cobertura vegetal (classes médias e baixas) com as áreas potenciais à saturação observa-se, por meio de análise visual, certa correlação espacial com os núcleos urbanos da bacia, tais como o caso do parcelamento urbano de Vicente Pires. A Figura 5 demonstra, para uma análise visual, a ocupação de 1984 e 2008, bem como o mapa de saturação do solo.

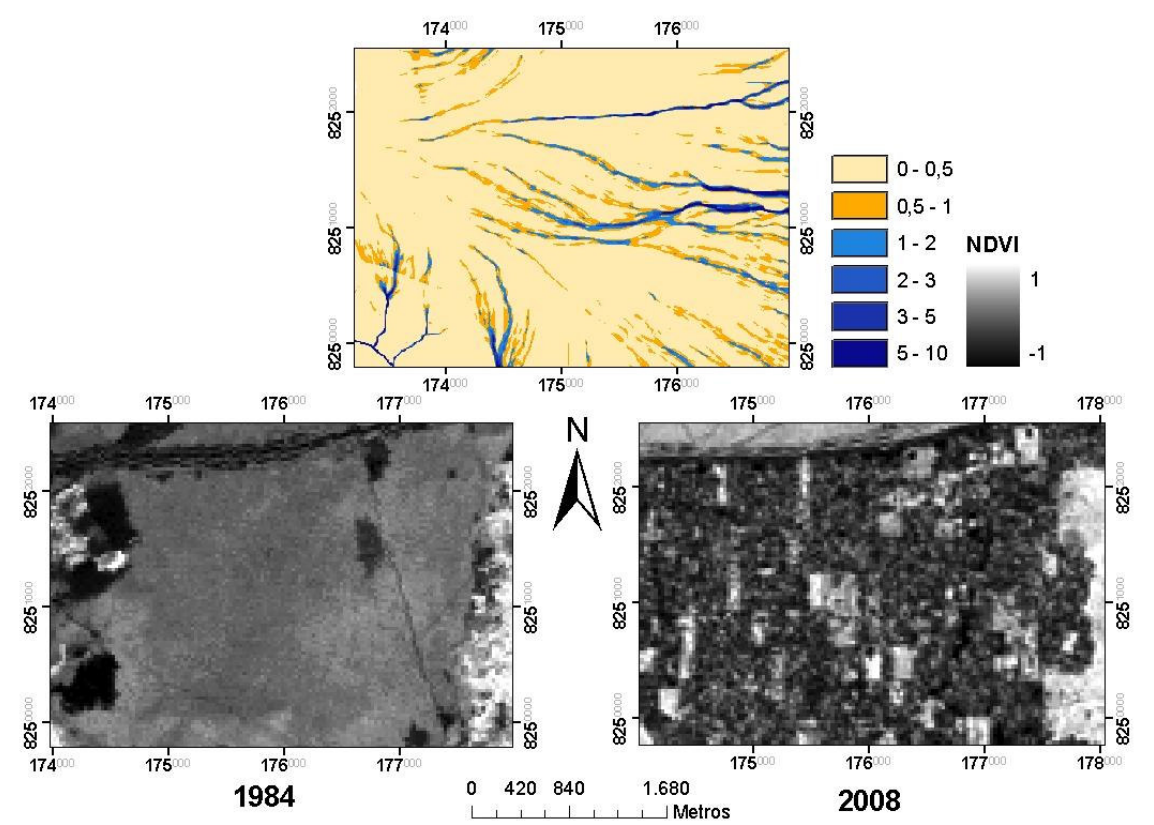

Figura 5 - Correlação visual entre NDVI e modelo de saturação na área urbanizada do Vicente Pires, nos respectivos anos de 1984 e 2008.

Segundo Tucci \& Clarke (1997) apud Lopes (2008), a cobertura vegetal possui um importante papel na interceptação da água no ciclo hidrológico, isto é, com interceptação maior o volume evaporado de água interceptada tende a ser maior, favorecendo o pico do hidrograma, consequentemente, reduzindo enchentes e aumentando a recarga para os rios, além de diminuir a erosão por salpicamento. Assim a retirada de grande parte da cobertura vegetal da classe de baixo índice fotossintético para a implantação urbana favorece o desequilíbrio do hidrograma, com a diminuição da interceptação natural e, conseqüente, aumento na probabilidade a erosões, ou acarretando conseqüências mais drásticas, se esta for vinculada a um sistema deficiente de drenagem urbana, tais como enchentes intra-urbanas.

\section{Considerações finais}

A utilização combinada de métodos referentes à cobertura vegetal, com modelagem matemática de saturação do solo, se mostrou coerente e eficaz, e pode servir de ferramenta de apoio em questões de gestão ambiental e territorial urbana, uma vez que são relativamente simples e de baixo custo.

O modelo de saturação do solo poderia ser aprimorado com a implantação de poços piezométricos para obtenção de dados de transmissividade dos solos, que por meio de interpolação, gerariam dados com maior nível de detalhamento e acurácia, refinando a metodologia proposta. 
Vale ressaltar que tal técnica não delega poder de decisão para os Sistemas de Informação Geográfica (SIG), uma vez que este é comandado pela modelagem matemática envolvida junto ao índice de vegetação utilizado.

\section{Referência bibliográfica}

Amaral, F. C. S.; Fernandes, L. A. C. Estudo da condutividade hidráulica dos solos na área do entorno do projeto de irrigação Salitre. Rio de Janeiro: Embrapa solos, 2007. 40 p. (ISSN 1678-0892).

Barbosa, F. L. R. Desenvolvimento de metodologia para delimitação de ottobacias a partir de modelo digital de elevação hidrologicamente consistente na bacia hidrográfica do rio Verde Grande. Monografia de final de curso, Universidade de Brasília, Instituto de Ciências Humanas - IH, Departamento de Geografia - GEA. Bacharelado, IH/GEA/UnB, 2007, 54p.

BRASIL. Empresa Brasileira de Pesquisa Agropecuária - EMBRAPA. Sistema Brasileiro de Classificação de Solos. Rio de Janeiro, Embrapa - CNPS. 412p. 1999.

BRASIL. Instituto Brasileiro de Geografia e Estatística - IBGE. Normas Cartográficas [On Line] < http://www.concar.ibge.gov.br/detalheDocumentos.aspx?cod=8>. Acesso em: 20 de abril 2009.

Damacena, F. A.;Guimarães, R. F.; Catão, R. C.; Gomes, R. A. T.; Barbosa, F. L. R.; Carvalho Júnior, O. A.; Martins, E. S.Delimitação de zonas de saturação na bacia do rio Jardim. In: Simpósio Brasileiro de Geomorfologia (SINAGEO), 7., 2008, Belo Horizonte. Anais... Belo Horizonte: UFMG, 2008.

Echeverria, R. M. Avaliação de impactos ambientais nos tributários do lago Paranoá, Brasília DF. 2007.121 p. Dissertação n 233 (Mestrado em Geociências/ Processamento de dados em geologia e análise ambiental) - Universidade de Brasília/ Instituto de Geociências, Brasília. 2007.

Freitas, L. F. Desenvolvimento de identificação de áreas com alta probabilidade de ocorrência de voçorocas em ambientes urbanos. Monografia de final de curso, Universidade de Brasília, Instituto de Ciências Humanas - IH, Departamento de Geografia - GEA. Bacharelado, IH/GEA/UnB, 2005, 38p.

Guerra, A. T.; Guerra, A. J. T. Novo dicionário geológico-geomorfológico. $3^{\text {a }}$ Edição. Rio de Janeiro: Bertrand Brasil, 2003. $652 \mathrm{p}$.

Guimarães, R. F.; Fernandes, N. F.; Gomes, R. A. T.; Carvalho Júnior, O. A. C. Fundamentação teórica do modelo matemático para previsão de escorregamentos rasos shallow stability. Espaço \& Geografia, v. 06, n. 02, p. 133-150, 2003.

Guimarães, R. F. Utilização de um modelo de previsão de áreas susceptíveis a escorregamentos rasos com controle topográfico: Adequação e calibração em duas bacias de drenagem. 2000. 156 p. Tese (Doutorado em Geografia) Universidade Federal do Rio de Janeiro/ Departamento de Geografia, Rio de janeiro. 2000.

Hutchinson, M. F. A new procedure for gridding elevation and stream line data with automatic removal of spurious pits. Journal of hydrology, v. 106, 211-232p, Elsevier Science Publishers B. V.. Amsterdam, 1989.

Lopes, N. H. Y. Análise da produção de água e sedimentos em microbacias experimentais com o modelo SWAT. 2007. 121 p. Dissertação $n^{0} 233$ (Mestrado em Geociências/ Processamento de dados em geologia e análise ambiental) Universidade de Brasília/ Instituto de Geociências, Brasília. 2007.

Maia, P. D.; Guimarães, E. M.; Moreira, R. C. A.; Boaventura, G. R. Estudo mineralógico dos sedimentos de fundo do lago Paranoá, Distrito Federal. Revista Brasileira de Geociências, v. 35, n. 4, p. 535-541, 2005.

Oliveira, L. A.; Campos, J. E. G. Parâmetros hidrogeológicos do sistema aquífero Bauru na região de Araguari/MG: Fundamentos para a gestão do sistema de abastecimento de água. Revista Brasileira de Geociências, v. 34, n. 2, p. 213-218, 2004.

O'loughlin, E. M. Prediction of surface saturation zones in natural catchments by topographic analysis. Water Resources Research. v. 22. 794-804. 1986.

Ponzoni, F. J. Comportamento Espectral da vegetação. In: Meneses, P. R [org].; Madeira Netto, J. S. [org.]. Sensoriamento remoto: reflectância dos alvos naturais. Brasília: UnB/ Embrapa Cerrados, 2001. 262 p.

Souza, M. L. ABC do desenvolvimento urbano. Rio de Janeiro: Bertrand Brasil, 2003. 192 p.

Tarboton, D. G. A new method for the determination of flow directions and upslope areas in the grid digital elevation models. Water Resources Research, v. 33, nº 2, 309-319p, 1997.

Vicens, R. S.; Cruz, C. B. M.; Rizzini, C. M. Utilização de técnicas de sensoriamento remoto na análise da cobertura vegetal da reserva florestal de Linhares, ES, Brasil. In: Simpósio Brasileiro de Sensoriamento Remoto (SBSR), 09, 1998, Santos. Anais... São José dos Campos: INPE, 1998. Artigos, p. 1561-1572. 